$$
3
$$


A JOURNAL OF RELIGION AND INTERNATIONAL AFFAIRS

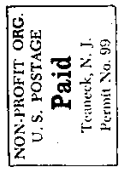

\section{THE CHURCH AS ACCOMPLICE}

\section{Gordon Zahn}

J. EDGAR HOOVER BROUGHT US TOGETHER

Rosemary Ruether

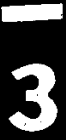

1
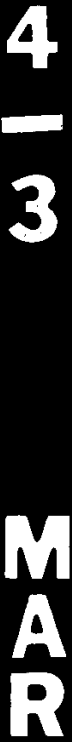

NIXON'S GRAND DESIGN

Donald Brandon

\section{N.P.T.: IMPOSSIBLE ALLIANCE?}

Frederick C. Thayer

\section{CHRISTIAN-MARXIST DIALOGUE}

Quentin Lauer, S.J. 